\title{
Comparing prophylactic effect of exercise and metformin on cognitive brain functions in rats with type 3 diabetes mellitus
}

\author{
Hader Ibrahim Sakr ${ }^{1}$, Mohamed A. Amen ${ }^{1}$, Laila A. Rashed ${ }^{2}$, Akef A. Khowailed ${ }^{1}$, Hazem A. Sayed ${ }^{3}$, \\ Moustafa E. Motawee ${ }^{4}$, Hany Sakr ${ }^{5}$, Mohamed Mansour Khalifa ${ }^{1}$
}

\begin{abstract}
${ }^{1}$ Department of Medical Physiology, Kasr Alainy Faculty of Medicine, Cairo University, Egypt

${ }^{2}$ Department of Biochemistry, Faculty of Medicine, Cairo University, Egypt

${ }^{3}$ Department of Anatomy and Embryology, Faculty of Medicine, Assiut University, Egypt ${ }^{4}$ Department of Histology and Cytology, Faculty of Medicine, Alazhar University, Egypt ${ }^{5}$ Department of Pathology and Laboratory Medicine, VAMC North East Ohio Healthcare System, Louis Stokes, Cleveland, Ohio, USA
\end{abstract}

Submitted: 29.07 .2019

Accepted: 26.03 .2020

Arch Med Sci

DOI: https://doi.org/10.5114/aoms.2020.99023

Copyright (c) 2020 Termedia \& Banach

\section{Abstract}

Introduction: Type 2 diabetes mellitus (DM) and Alzheimer's disease (AD) are two major medical conditions that constitute a significant financial burden on most healthcare systems. Due to AD sharing "insulin resistance" mechanistic features with DM, some scientists have proposed "type 3 DM" terminology for it. This study aims to compare the prophylactic effect of exercise and metformin on cognitive brain functions in rats with type $3 \mathrm{DM}$. Material and methods: Two groups of rats were included in the study: the control group $(n=15)$ and the streptozotocin-induced type 2 diabetic group $(n=45)$. The diabetic group was subdivided into three equal subgroups: a sedentary non-treated diabetic group, an exercised group, and a metformin-treated group. We estimated step-down avoidance task latency, serum glucose, insulin, free fatty acids (FFA), cholesterol, high-density lipoprotein (HDL), low-density lipoprotein (LDL) and triglycerides (TG), brain A $\beta-42$ and glucose, histological changes by toluidine blue, and immunohistochemistry for brain A $\beta-42$ and tau-positive cells.

Results: Serum glucose, FFA, TG, cholesterol, LDL, brain A $\beta-42$, brain glucose, the number of hippocampal dark and degenerated cells, and brain A $\beta-42$ and tau-positive cells, were all significantly lower. In contrast, serum insulin and HDL, the number of hippocampal granular cells, and latency of the step-down avoidance task were significantly higher in exercised and metformin-treated groups compared to the diabetic group. There were significantly higher values of serum insulin and brain/plasma glucose ratio and number of brain tau-positive cells in the metformin-treated group than in the exercised group.

Conclusions: We can conclude that exercise can be as effective as metformin regarding prophylaxis against the deleterious effects of type 3 DM on cognitive brain functions.

Key words: diabetes mellitus, Alzheimer's disease, treadmill exercise, metformin, hippocampus.

\author{
Corresponding author: \\ Hader Ibrahim Sakr MD, PhD \\ Lecturer of Medical Physiology \\ Department \\ of Medical Physiology \\ Kasr Alainy Faculty \\ of Medicine \\ Cairo University \\ AL-Saraya Street, Old Cairo, \\ Cairo Governorate, 11562, \\ Egypt \\ Phone: (002) 011-11616364 \\ Fax: (002) 272-72148 \\ E-mail: hadersakr@ \\ kasralainy.edu.eg
}




\section{Introduction}

Type 2 diabetes mellitus (T2DM) and Alzheimer's disease $(A D)$ are two medical diseases that have significant drawbacks in modern healthcare systems [1]. In 2014, the average healthcare-related cost for individuals with DM was between $\$ 1,583$ and $\$ 2,842$ worldwide [2]. Type $2 \mathrm{DM}$ is attributed to insulin resistance, which has also been documented for $A D$, making some scientists represent $A D$ as "type 3 DM" or "brain-specific type 2 DM". This hypothesis has been reinforced by a plethora of findings that have been occurring over the past few years, highlighting the presence of several shared molecular pathways [3].

High insulin levels in the brain have been recently proven to play a vital role in cognitive functions. In addition, insulin has been shown to have in utero protective function against oxidative stress-mediated through insulin receptor (IR) signaling pathways [4]. The majority of brain insulin is actively transported across the bloodbrain barrier (BBB). However, a trace amount of peripherally synthesized insulin passively diffuses through the area postrema [5]. The hippocampal pyramidal neurons synthesize and release intracerebral insulin, which binds rapidly to the widely distributed IR receptors [6]. In T2DM, insulin uptake by the brain is downregulated. This deprives the highly metabolic limbic system neurons of the fuel required for their proper functions. This is translated clinically in the form of progressive deterioration of learning, memory, and cognitive brain functions [7]. Dysregulation of insulin signaling pathways has been recently claimed as a neuropathological hallmark for the progressive development of $A D$, tau protein hyper-phosphorylation, and $\beta$-amyloid (A $\beta$ ) deposition. Insulin/IR dysregulation has been located to defective processing of $A \beta$ precursor protein (A $\beta-P P)$, leading to misfolded $A \beta$ accumulation [8]. Furthermore, the increased amount of misfolded $A \beta$ protein competes with insulin for the insulin-degrading enzyme (IDE), which usually degrades both insulin and $A \beta$. Consequently, this leads to $A B$ peptide deposition and formation of senile plaques, the histologic hallmark of AD [9].

Physical activity has a well-known, potent effect in alleviating neurological symptoms and counteracting pathologic consequences of impaired glucose tolerance and T2DM [10]. It was reported that regular exercise improved cognitive functions in elderly patients, in addition to its beneficial effects on vascular physiology, endothelial function, and neurovascular coupling [11]. Treadmill exercise decreased the incidence of $A D$ by suppressing glycogen synthase kinase- $3 \beta$ expression in streptozotocin-induced diabetic rats. This has been linked to increased insulin sensitivity and enhanced downstream signaling [1].

Metformin is a member of the biguanide family of hypoglycemic drugs that is widely used worldwide in the management of T2DM [12] and metabolic syndrome [13]. It is a highly effective drug with an excellent safety profile, few side effects, and a low risk of inducing hypoglycemia. One of metformin's mechanisms of action is to inhibit insulin-mediated hepatic glucose output. In addition, it enhances peripheral glucose utilization, leading to an efficient reduction of blood glucose levels and better glycemic control [14].

At the molecular level, metformin has a strong inhibitory effect on mitochondrial electron-transport-chain protein "complex I" in the liver, with subsequent suppression of adenosine triphosphate (ATP) production. Metformin also upregulates the production of AMP-activated protein kinase (AMPK), an essential regulator of glucose metabolism [15]. Metformin has been shown to play similar roles in the central nervous system (CNS), protecting brains of rats with streptozotocin-induced DM against oxidative stress. However, the exact mechanisms of these protective effects still need further investigation [16].

The current study aims at comparing the prophylactic effect of treadmill exercise and metformin medication on cognitive brain functions in male albino rats with type $3 \mathrm{DM}$.

\section{Material and methods}

\section{Animal care and housing}

Sixty adult male albino rats, seven weeks old, and weighing $200 \mathrm{~g}( \pm 10 \mathrm{~g})$ were obtained from the animal care and use facility at Kasr Al-Ainy Faculty of Medicine, Cairo University, Egypt. Rats were kept under observation for 15 days prior to onset of experiments for adaptation and exclusion of any current infection. Rats were housed in plastic cages (3 rats/cage) under optimal temperature $\left(25 \pm 5^{\circ} \mathrm{C}\right)$ and humid conditions with 12 hours alternating light and dark cycles. Rats were given free water access and supplied daily with laboratory rat diet offered ad-lib. The experimental protocol used in this study was approved by the Institutional Animal Care and Use Committee (CU-IACUC), Cairo University, with approval number: CU/III/F/68/18.

\section{Animal grouping}

The study animals were divided into two groups: a normal control group (Group I, $n=15$ ): non-diabetic male albino rats, not put under treadmill exercise, and a streptozotocin (STZ)-induced type 2 DM group (Group II): a total of 45 male albino rats were placed on high-fat diet 
(HFD) for two weeks, followed by a single intraperitoneal (IP) injection of low-dose streptozotocin $(30 \mathrm{mg} / \mathrm{kg})$ in $0.01 \mathrm{M}$ citrate buffer ( $\mathrm{pH}$ of 4.3$)$; to induce type 2 DM (HFD + STZ). After STZ treatment, rats were continued on their respective diets for the study duration of twelve weeks [17]. T2DM was confirmed, on day 20 , by measuring fasting plasma glucose and insulin levels. Only animals with blood glucose levels $\geq 300 \mathrm{mg} / \mathrm{dl}$ were used as the diabetic group [1]. This group was further subdivided into the following subgroups (15 rats each):

- DM control group (diabetic group, Ila): no exercise and no treatment;

- DM with exercise group (exercised-group, IIb): rats were put on a treadmill for $30 \mathrm{~min} /$ day, five days/week, for the study duration. The exercise program included running at a speed of $3 \mathrm{~m} / \mathrm{min}$ for the first $5 \mathrm{~min}, 5 \mathrm{~m} / \mathrm{min}$ for the next $5 \mathrm{~min}$, and then $8 \mathrm{~m} / \mathrm{min}$ for the last $20 \mathrm{~min}$, with $0 \%$ grade of inclination [1];

- DM with metformin treatment group (metformin-treated group, IIc): rats in this group received $1.5 \mathrm{mg}$ metformin/kg once daily, by gavage, for the study duration [18].

\section{Step-down avoidance task latency}

To evaluate the memory function following each experiment, rats were placed on a $7 \times 25 \mathrm{~cm}$ platform with a height of $2.5 \mathrm{~cm}$ and were allowed to rest for $1 \mathrm{~min}$ on the platform. Platforms faced a $42 \times 25 \mathrm{~cm}$ grid of parallel stainless steel bars with $0.1 \mathrm{~cm}$-caliber, spaced apart by $1 \mathrm{~cm}$ distance.

In the training session, rats received a $0.5 \mathrm{~mA}$ foot shock for $2 \mathrm{~s}$ immediately upon stepping off of the platform. Latency was assessed at 2 and 48 hours after the training session. The interval between rats stepping down the platform and placing all four paws on the grid was defined as the latency in the step-down avoidance task. Any latency over $300 \mathrm{~s}$ was counted as $300 \mathrm{~s}$ [19].

\section{Blood sampling}

Heparinized capillary tubes were used to collect blood samples from retro-orbital spaces. Blood samples were centrifuged at 10,000 rpm for $15 \mathrm{~min}$, and serum was separated and stored at $-70^{\circ} \mathrm{C}$. Each serum sample was divided equally into three tubes for further testing.

\section{Measurement of parameters}

Serum blood glucose was measured using the enzymatic method. Briefly, glucose oxidase was used to catalyze the oxidation of glucose to hydrogen peroxide and gluconic acid. Hydrogen peroxide, when combined with 4-amino antipyrine and a phenol derivative, forms a red dye compound that can be measured by spectrophotometer. The intensity of red color generated is directly proportional to the glucose concentration in the sample. Serum concentration of $60-110 \mathrm{mg} / \mathrm{dl}$ was considered the normal reference range [20]. Serum FFA was measured according to Sfa [21]. Serum $\mathrm{HDL}$ and cholesterol were measured according to Young [22]. Serum triglycerides were measured according to Fossati and Principe [23]. Brain glucose was measured according to Fray et al. [24]. Brain amyloid $\beta 1-42$ levels were measured according to Best et al. [25].

\section{Toluidine blue staining}

Isolated rat brains were fixed in $4 \%(\mathrm{w} / \mathrm{v})$ paraformaldehyde, and then cut into tissue slices at 4 microns thick for toluidine blue staining. Slices were incubated with a $0.5 \%(\mathrm{w} / \mathrm{v})$ toluidine blue solution at $56^{\circ} \mathrm{C}$ for $20 \mathrm{~min}$. After dehydration, washing and mounting on glass slides, brain slices were examined under light microscopy. Morphological changes in hippocampal neurons in CA3 area were detected [26].

\section{Immunohistochemical techniques}

Tissue preparation: Rats' brains were removed and fixed overnight in formaldehyde solution, then transferred into a $30 \%$ sucrose solution for cryoprotection. Serial coronal sections of $4 \mu \mathrm{m}$ thickness were made using a freezing microtome (Leica, Nussloch, Germany).

Immunohistochemistry staining for brain $A \beta$ depositions: Slides were incubated with the primary mouse anti-AB antibody (39320, Covance Inc, USA) at $4^{\circ} \mathrm{C}$ for 12 hours. After incubation, slides were washed in $0.01 \mathrm{M}$ phosphate buffered saline (PBS) solution 3 times for 5 min each, and secondary horseradish peroxidase (HRP)-labeled goat anti-mouse antibodies were added (sc-2005, Santa Cruz, CA, USA) at room temperature for one hour [27].

Immunohistochemistry staining for brain tau-positive cells: Following incubation with the primary antibody, sections were incubated for 90 min with biotinylated anti-rabbit secondary antibody (1 : 200; Vector Laboratories, Burlingame, CA, USA). The secondary reaction was amplified with a Vector Elite ABC kit (1:100; Vector Laboratories). The antibody-biotin-avidin-peroxidase complexes were visualized using $0.03 \%$ diaminobenzidine (DAB). Finally, the stained tissue sections were mounted onto gelatin-coated slides. The slides were air dried overnight at room temperature, and then coverslipped using Permount (Fisher Scientific, Fairlawn, NJ, USA) [28].

The total number of granular, apoptotic, degenerated, and tau-positive cells, as well as A $\beta$ depo- 
sitions in dentate gyrus, was calculated hemilaterally using an Image-Pro Plus computer-assisted image analysis system (Media Cyberbetics Inc., Silver Spring, MD) [29].

\section{Statistical analysis}

Data were coded and entered using the statistical package SPSS version 24. Data were summarized using mean and standard deviation for quantitative variables and frequencies (number of cases) and relative frequencies (percentages) for categorical variables. One-way ANOVA was done to find out any statistically significant difference between the mean value of data of different groups. $P$-values less than 0.05 were considered statistically significant. A post hoc test was done to find out the level of inter-group significant difference [30].

\section{Results}

\section{Physical experiment}

The diabetic group showed significant lower latency in the step-down avoidance test, both
2 and 48 hours after exercise $(-27.85 \%$ and $-44.5 \%$ respectively), compared to the control group. However, rats put under regular exercise, and the metformin-treated group did not show any significant difference compared to the control group. On the other hand, the results showed significant higher latency in the exercise $(+34.65 \%$ and $+87.5 \%$ respectively) and metformin-treated $(+36.83 \%$ and $+78.8 \%$ respectively) groups compared to the diabetic group. Last, there was no significant difference between the exercise and metformin-treated groups (Table I and Figure 1).

\section{Biochemical studies}

\section{Serum glucose levels}

There was a significant higher serum glucose levels in the diabetic (+153.87\%), exercise $(+44.91 \%)$, and metformin-treated (+31.54\%) groups, as compared to the control group. As expected, there was a significant lower serum glucose levels in both exercise $(-43.08 \%)$ and metformin-treated $(-48.33 \%)$ rats compared to the diabetic group. Interestingly, there was no signif-

Table I. Comparison of different parameters among the studied groups

\begin{tabular}{|c|c|c|c|c|}
\hline Parameters & Control & Diabetic & Exercise & Metformin \\
\hline \multicolumn{5}{|c|}{$\begin{array}{l}\text { Step-down avoidance test after } \\
\text { training (s) }\end{array}$} \\
\hline 2 hours & $293.84 \pm 6.06$ & $212.02 \pm 57.38^{*}$ & $285.48 \pm 10.18^{\#}$ & $290.10 \pm 11.76^{\#}$ \\
\hline 48 hours & $246.32 \pm 8.99$ & $136.78 \pm 54.12^{*}$ & $256.42 \pm 15.45^{\#}$ & $244.56 \pm 23.19^{\#}$ \\
\hline Serum glucose (mg/dl) & $105.96 \pm 11.88$ & $269.75 \pm 29.47^{\star}$ & $153.55 \pm 10.92^{\text {*\# }}$ & $139.38 \pm 21.92^{\text {*\# }}$ \\
\hline \multicolumn{5}{|l|}{ Lipid profile } \\
\hline FFA $(\mu \mathrm{mol} / \mathrm{l})$ & $38.84 \pm 5.31$ & $111.68 \pm 12.34^{*}$ & $80.89 \pm 10.91^{\star \#}$ & $69.91 \pm 15.57^{\text {*\# }}$ \\
\hline Cholesterol (mg/dl) & $94.20 \pm 59.42$ & $240.90 \pm 27.07^{\star}$ & $178.40 \pm 14.03^{\text {*\# }}$ & $171.00 \pm 14.45^{\text {*\# }}$ \\
\hline $\mathrm{TG}(\mathrm{mg} / \mathrm{dl})$ & $75.60 \pm 4.62$ & $110.20 \pm 14.41^{*}$ & $94.80 \pm 12.85^{\text {*\# }}$ & $90.90 \pm 10.24^{\#}$ \\
\hline $\mathrm{LDL}(\mathrm{mg} / \mathrm{dl})$ & $81.42 \pm 8.09$ & $187.59 \pm 27.62^{*}$ & $112.98 \pm 14.31^{\text {*\# }}$ & $103.58 \pm 14.54^{\#}$ \\
\hline $\mathrm{HDL}(\mathrm{mg} / \mathrm{dl})$ & $57.66 \pm 3.51$ & $31.27 \pm 5.56^{\star}$ & $47.18 \pm 6.06^{\star \#}$ & $49.24 \pm 4.45^{\text {*\# }}$ \\
\hline Brain glucose (mg/dl) & $57.16 \pm 6.18$ & $145.11 \pm 18.79^{*}$ & $80.24 \pm 8.19^{\star \#}$ & $83.15 \pm 10.16^{\text {*\# }}$ \\
\hline Brain $A \beta-42(\mathrm{pg} / \mathrm{ml})$ & $1.50 \pm 0.40$ & $10.41 \pm 2.20^{\star}$ & $4.50 \pm 1.70^{\text {*\# }}$ & $4.54 \pm 1.65^{\text {*\# }}$ \\
\hline \multicolumn{5}{|c|}{$\begin{array}{l}\text { Toluidine blue cell counting } \\
\text { (cells/10 } \mathrm{mm}^{2} \text { ) }\end{array}$} \\
\hline Granular & $100.83 \pm 11.97$ & $55.67 \pm 5.05^{\star}$ & $85.17 \pm 6.11^{\text {*\# }}$ & $86.67 \pm 5.85^{\text {*\# }}$ \\
\hline Dark & $8.83 \pm 2.32$ & $27.5 \pm 3.78^{\star}$ & $12.33 \pm 2.16^{\star \#}$ & $15.83 \pm 3.87^{\star \#}$ \\
\hline Degenerated & $5.5 \pm 2.07$ & $22.67 \pm 4.27^{\star}$ & $10.33 \pm 1.63^{* \#}$ & $11.83 \pm 3.06^{\text {*\# }}$ \\
\hline \multicolumn{5}{|c|}{$\begin{array}{l}\text { Immunohistochemistry for brain } \\
\left(\text { cells } / \mathrm{mm}^{2} \text { ) }\right.\end{array}$} \\
\hline$A \beta-42+v e$ & $115.09 \pm 7.86$ & $373.74 \pm 17.25^{*}$ & $245.81 \pm 14.48^{\text {*\# }}$ & $248.72 \pm 15.52^{\text {*\# }}$ \\
\hline Tau +ve & $62.95 \pm 6.42$ & $198.64 \pm 19.53^{*}$ & $142.33 \pm 11.79^{\text {*\# }}$ & $170.72 \pm 14.57^{\star \$}$ \\
\hline
\end{tabular}

Values are presented as mean $\pm S D$. *statistically significant compared to the corresponding value in the control group ( $p<0.05$ ); "statistically significant compared to the corresponding value in the diabetic group $(p<0.05)$; 'statistically significant compared to the corresponding value in the exercise group $(p<0.05)$. 
A

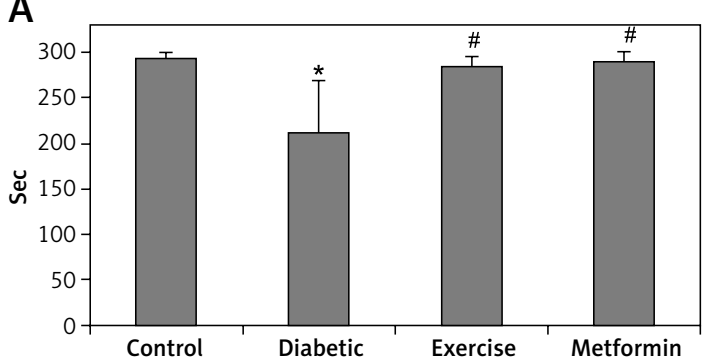

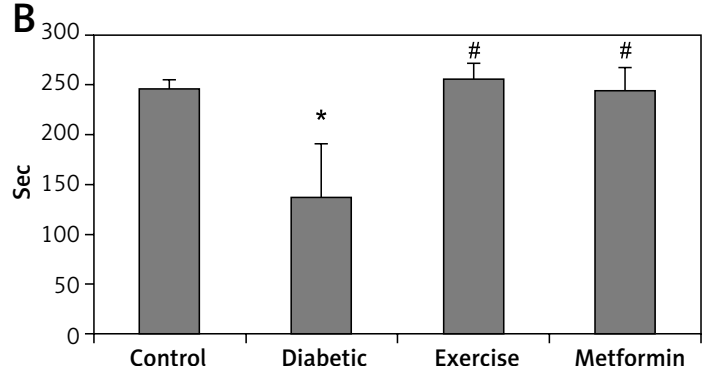

Figure 1. Changes in the mean of step-down avoidance task: $\mathbf{A}-2$ hours, and $\mathbf{B}-48$ hours among the study groups Values are presented as mean $\pm S D$. *statistically significant compared to the corresponding value in the control group ( $p<0.05)$;

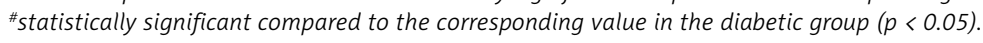

icant difference in serum glucose levels between the exercise and metformin-treated groups (Table I and Figure 2).

\section{Lipid profile}

Our results showed a significant higher serum FFA and cholesterol levels in the diabetic $(+187.5 \%$ and $+155.73 \%$ respectively), exercise $(+108.26 \%$ and $+89.38 \%$ respectively), and metformin-treated $(+79.99 \%$ and $+81.53 \%$ respectively) groups compared to the control group. On the other hand, the present study showed a significant lower FFA and cholesterol levels in both exercise $(-27.57 \%$ and $-25.94 \%$ respectively) and metformin-treated $(-37.4 \%$ and $-29.01 \%$ respectively) groups compared to the diabetic group. There was no significant difference in serum FFA and cholesterol levels between the exercise and metformin-treated groups (Table I and Figure 3 ).

Serum TG and LDL levels showed a significant higher the diabetic $(+45.7 \%$ and $+130.4 \%$ respectively) and exercise $(+25.4 \%$ and $+38.76 \%$ respectively) groups compared to the control group. Also, there was a significant lower serum TG and LDL levels in both exercise $(-13.97 \%$ and $-39.77 \%$ respectively) and metformin-treated $(-17.51 \%$ and $-44.69 \%$ respectively) groups compared to the diabetic group. Interestingly, there was no significant lower

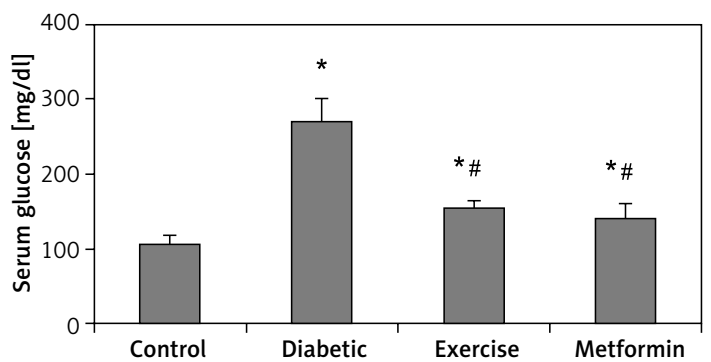

Figure 2. Differences in serum glucose levels among the study groups

Values are presented as mean $\pm S D$. *statistically significant compared to the corresponding value in the control group ( $p<0.05)$; "statistically significant compared to the corresponding value in the diabetic group $(p<0.05)$.

serum levels of both TG and LDL among metformin-treated, control, and exercise groups (Table I and Figure 4).

Our results demonstrated a significant lower serum HDL levels in the diabetic (-45.77\%), exercise $(-18.17 \%)$, and metformin-treated $(-14.6 \%)$ groups compared to the control group. At the same time, there was a significant higher HDL serum levels in both exercise $(+50.88 \%)$ and metformin-treated $(+57.5 \%)$ groups compared to the diabetic group. The results showed no significant difference in HDL serum levels between the exer-
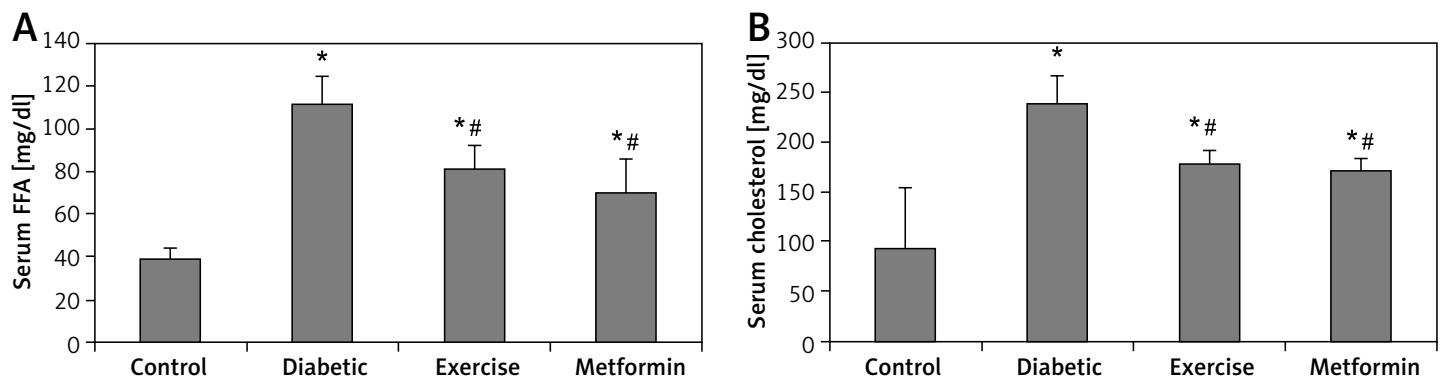

Figure 3. Changes in the mean of serum: A - FFA and B - cholesterol among the study groups

Values are presented as mean $\pm S D$. *statistically significant compared to the corresponding value in the control group ( $p<0.05)$; "statistically significant compared to the corresponding value in the diabetic group $(p<0.05)$. 

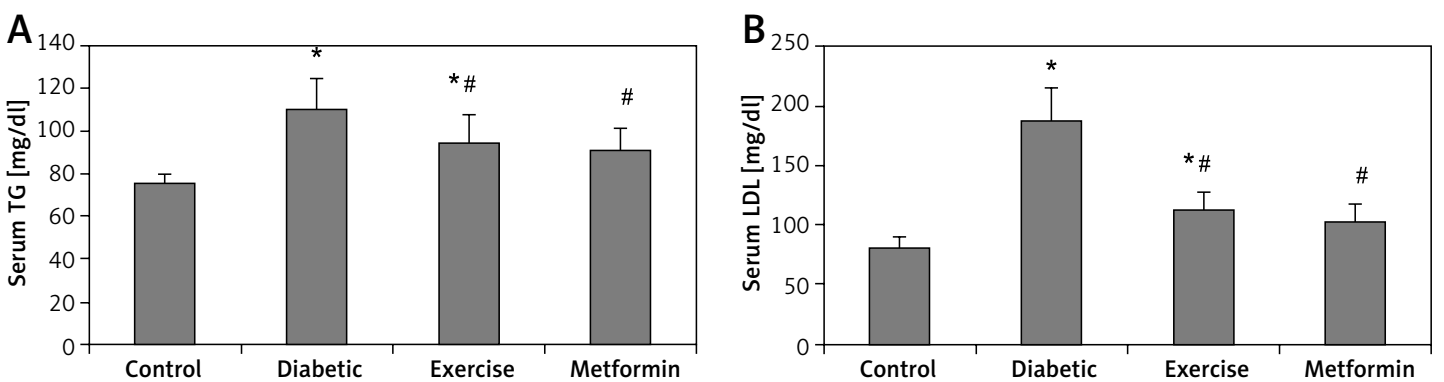

Figure 4. Changes in the mean of serum: A - TG, B - LDL in the adult rats of the experimental groups

Values are presented as mean $\pm S D$. *statistically significant compared to the corresponding value in the control group ( $p<0.05)$; "statistically significant compared to the corresponding value in the diabetic group $(p<0.05)$.

cise and metformin-treated groups (Table I and Figure 5).

\section{Brain glucose and $A \beta-42$ levels}

The current study showed a significant higher brain glucose and $A \beta-42$ levels in diabetic $(+153.87 \%$ and $+594 \%$ respectively), exercise $(+40.38 \%$ and $+200 \%$ respectively) and metformin-treated $(+45.47 \%$ and $+304 \%$ respectively) groups when compared to the control group. Additionally, the results showed a significant lower glucose and A $\beta-42$ levels in the

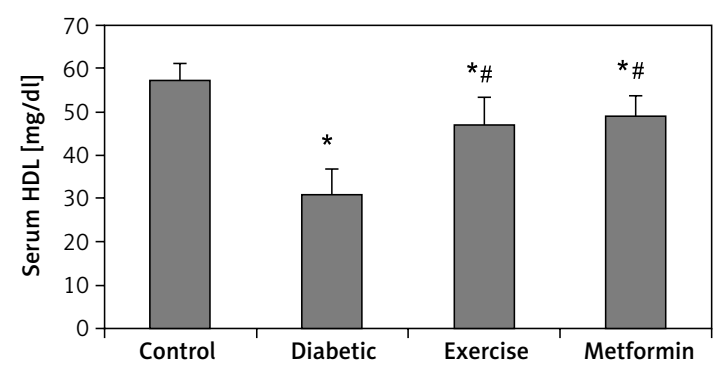

Figure 5. Changes in the mean of serum HDL among the study groups

Values are presented as mean $\pm S D$. *statistically significant compared to the corresponding value in the control group ( $p<0.05)$; "statistically significant compared to the corresponding value in the diabetic group $(p<0.05)$.

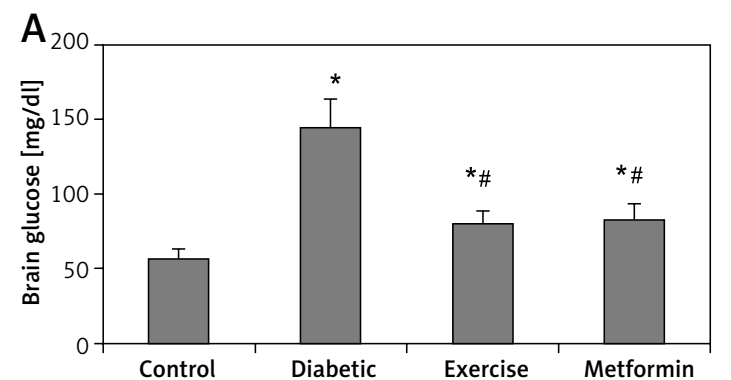

brains of rats put under exercise $(-44.7 \%$ and $-56.77 \%$ respectively) or treated with metformin $(-42.7 \%$ and $-56.38 \%$ respectively) compared to the diabetic group. There was no significant difference in hippocampal A $\beta-42$ levels between the exercise and metformin-treated groups (Table I and Figure 6).

\section{Toluidine blue staining and cell counting}

\section{Hippocampal granular cells}

The present study demonstrated a significant fewer hippocampal granular cells in diabetic $(-44.79 \%)$, exercise $(-15.53 \%)$, and metformin-treated $(-14.04 \%)$ groups compared to the control group. The results also showed a significant greater hippocampal granular cells in both exercise $(+52.99 \%)$ and metformin-treated $(+55.69 \%)$ groups compared to the diabetic group. We did not see any significant difference in hippocampal granular cell numbers between exercise and metformin-treated groups (Table I and Figures $7 \mathrm{~A}$ and 8).

\section{Hippocampal dark and degenerated cells}

The study also demonstrated a significant greater hippocampal dark and degenerated cells in diabetic $(+211.44 \%$ and $+312.18 \%$, respectively), exercise $(+39.64 \%$ and $+87.82 \%$ respectively) and metformin-treated $(+79.28 \%$ and $+115.09 \%$

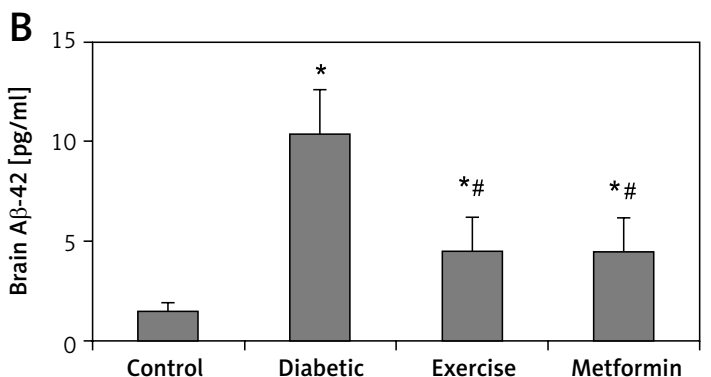

Figure 6. Changes in the mean of the brain: $\mathbf{A}$ - glucose, and $\mathbf{B}-\mathrm{A} \beta-42$ levels among the study groups Values are presented as mean $\pm S D$. *statistically significant compared to the corresponding value in the control group ( $p<0.05)$; "statistically significant compared to the corresponding value in the diabetic group $(p<0.05)$. 

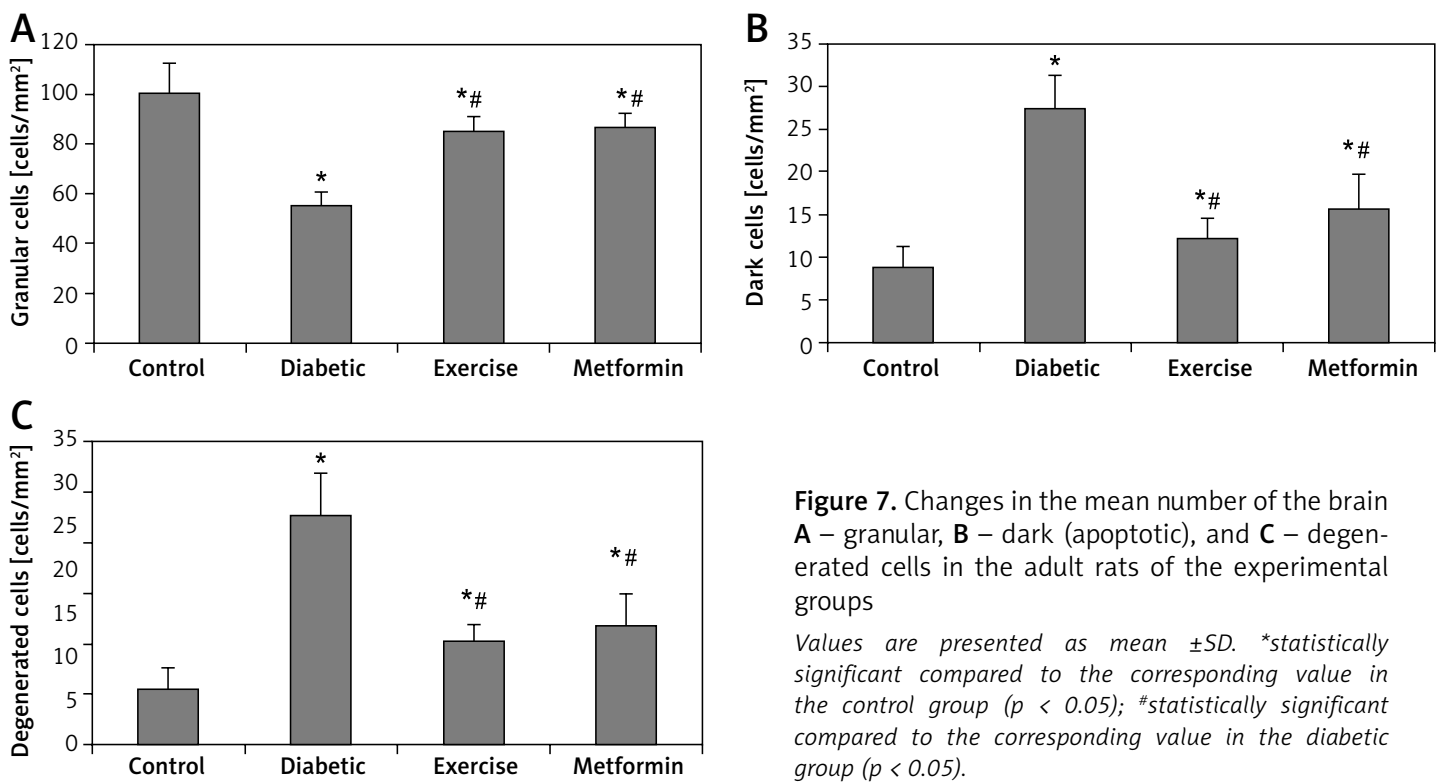

Figure 7. Changes in the mean number of the brain A - granular, B - dark (apoptotic), and C - degenerated cells in the adult rats of the experimental groups

Values are presented as mean $\pm S D$. *statistically significant compared to the corresponding value in the control group ( $p<0.05)$; "statistically significant compared to the corresponding value in the diabetic group $(p<0.05)$.
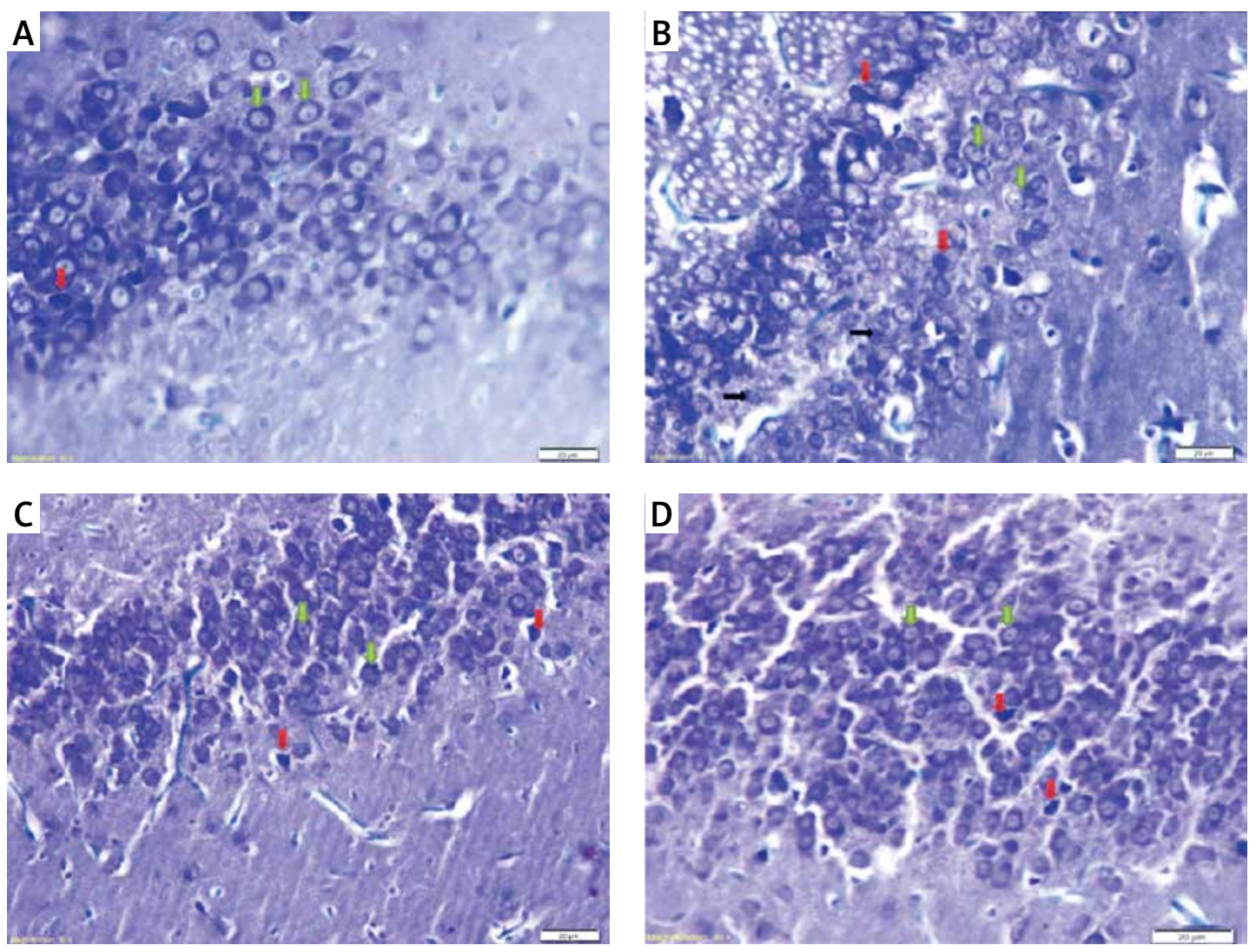

Figure 8. Photomicrograph of sections of the dentate gyrus stained with toluidine blue showing: A - normal thickness of granular cell layer, normal granular cells (green arrows) and dark (apoptotic) cells (red arrow) in control rats. B - normal pyramidal cells (green arrows), degenerated cells (black arrows), apoptotic cells (red arrows) and multiple cavitations in diabetic group. C - normal granular cells (green arrows) and some dark (apoptotic) cells (red arrows) in diabetic exercise group. D - normal granular cells (green arrows) and some apoptotic cells (red arrows) in diabetic metformin-treated group (Toluidine blue, 400x)

respectively) groups when compared to the control group. Yet, there was a significant fewer dark and degenerated cells in both exercise $(-55.16 \%$ and $-54.43 \%$ respectively) and metformin-treated $(-42.44 \%$ and $-47.82 \%$ respectively) rat groups compared to the diabetic group. There was no significant difference in the numbers of hippocampal dark and degenerated cells between exercise and metformin-treated groups (Table I and Figures 7 $B, C$ and 8). 

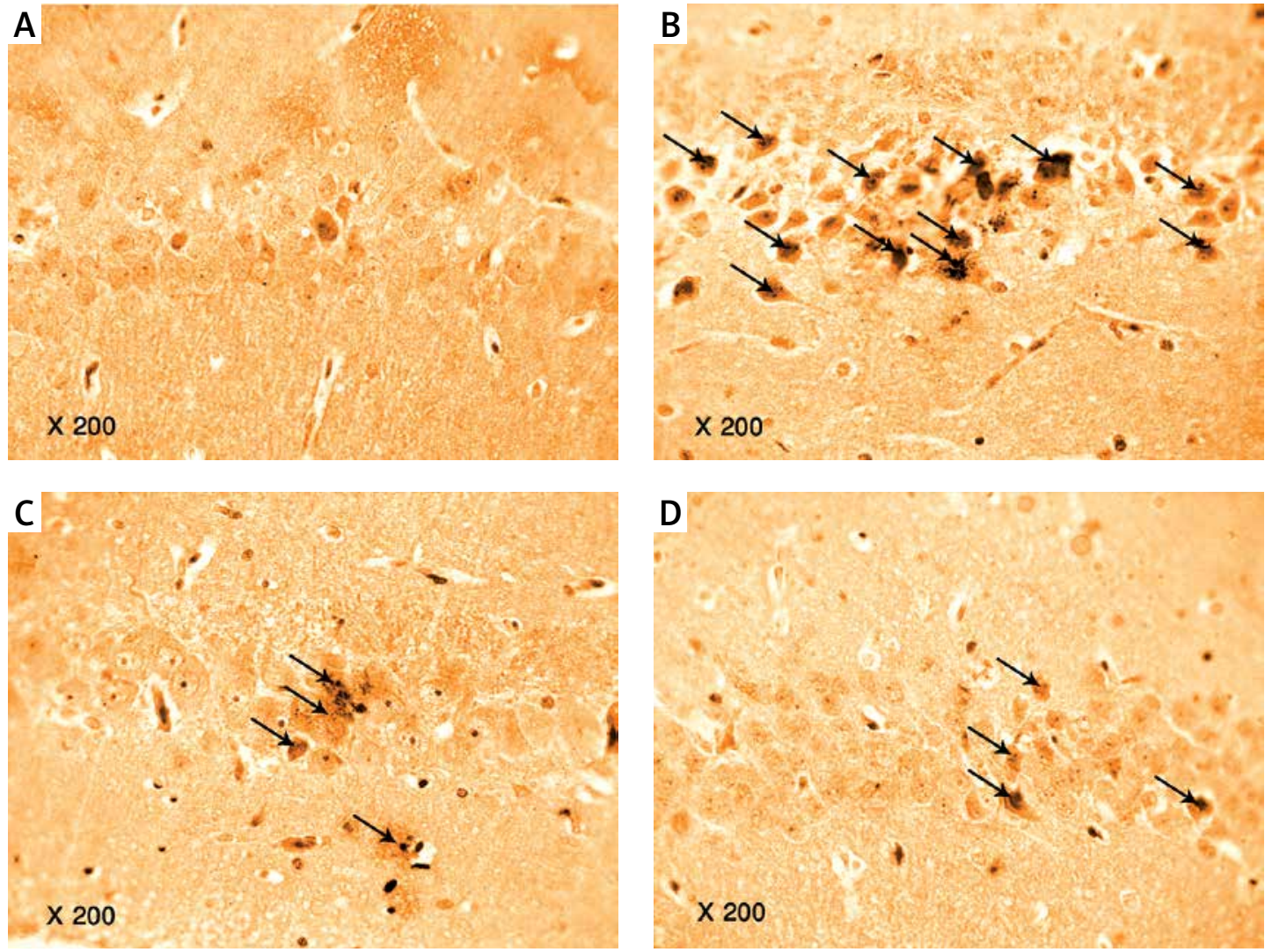

Figure 9. Photomicrograph of a cryo-section of the dentate gyrus of A - Control rats, B - Diabetic group, C - Diabetic exercise group, and $\mathbf{D}$ - Diabetic metformin-treated group showing positive immunoreactivity of neurons in the form of brown staining of cytoplasmic A $\beta-42$ (arrows) (Immunohistochemical stain, Counterstained with Hx., 200x)

\section{Immunohistochemistry}

Immunohistochemistry for hippocampal A $\beta-42$ protein

The results of the current study showed a significant greater hippocampal A $A-42$ immunohistochemistry (IHC) positive cells in diabetic $(+224.74 \%)$, exercise $(+113.6 \%)$, and metformintreated $(+116.1 \%)$ groups compared to the con- trol group. Excitingly, there was a significant fewer hippocampal $A \beta-42$ positively staining cells in both the exercise $(-34.23 \%)$ and metformin-treated $(-33.45 \%)$ groups when compared to the diabetic group. Noticeably, there was no significant difference in the number of hippocampal A $\beta-42$ positive cells between exercise and metformin-treated groups (Table I and Figures 9 and 10).

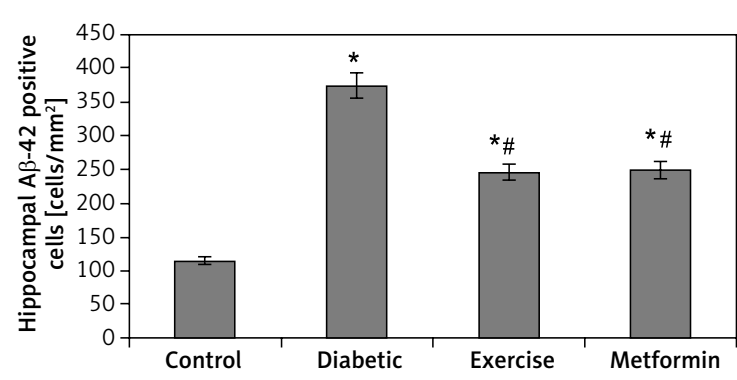

Figure 10. Changes in the mean number of brain A $\beta-42$ positive cells in the adult rats of the experimental groups

Values are presented as mean $\pm S D$. *statistically significant compared to the corresponding value in the control group ( $p<0.05)$; "statistically significant compared to the corresponding value in the diabetic group $(p<0.05)$.

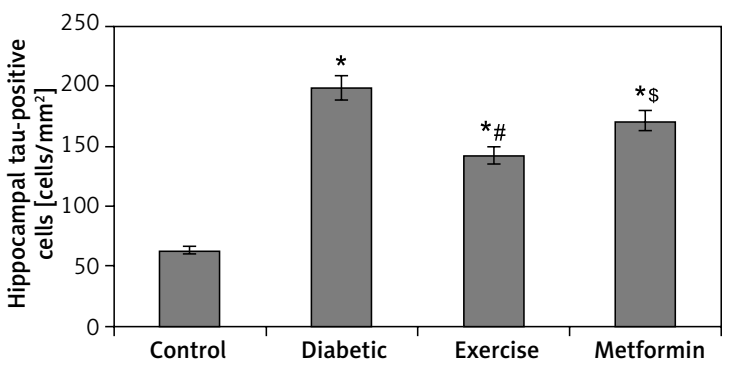

Figure 11. Changes in the mean number of brain tau-positive cells in the adult rats of the experimental groups

Values are presented as mean $\pm S D$. *statistically significant compared to the corresponding value in the control group ( $p<0.05)$; "statistically significant compared to the corresponding value in the diabetic group ( $p<0.05)$; 'statistically significant compared to the corresponding value in the exercise group $(p<0.05)$. 

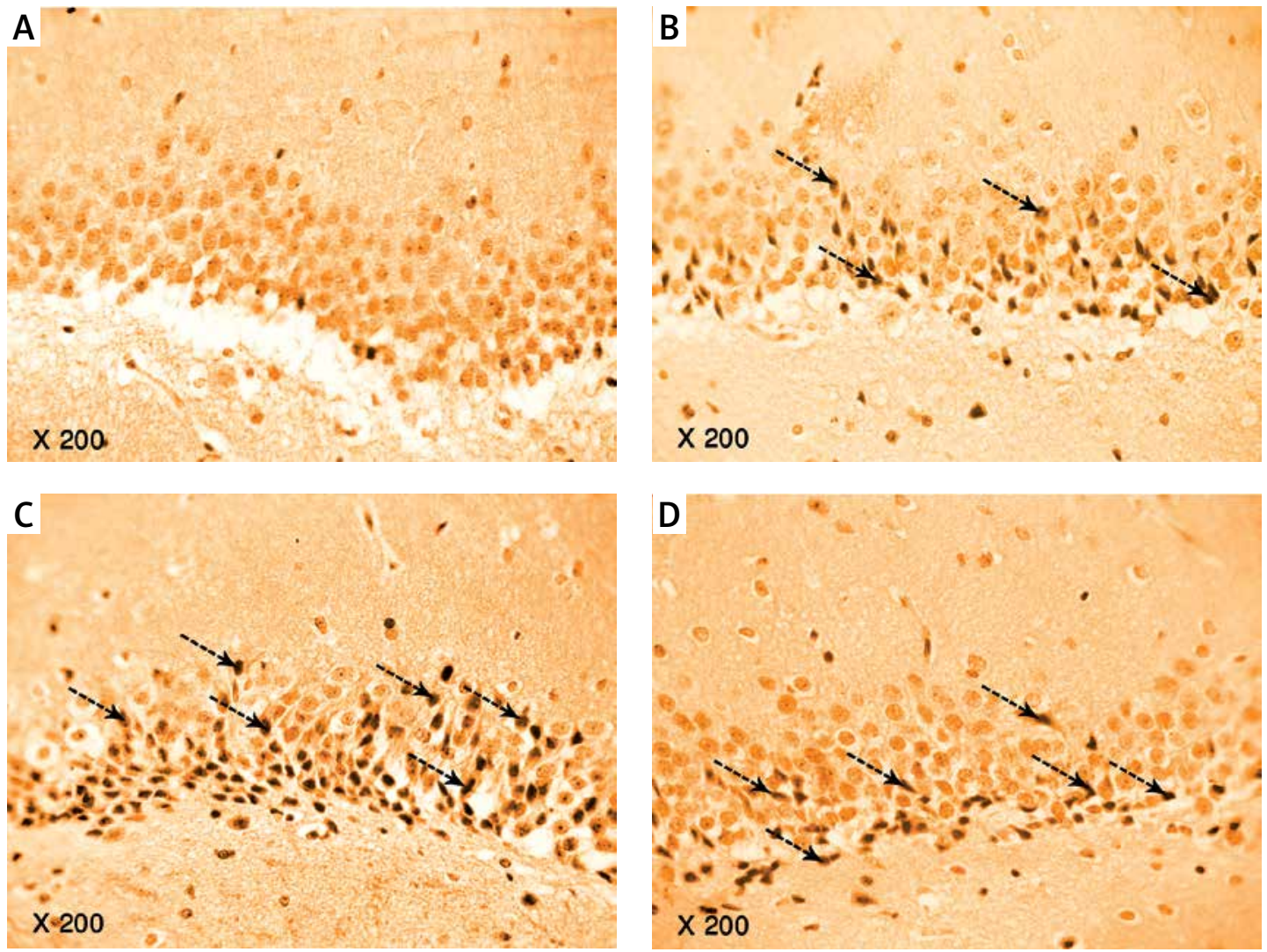

Figure 12. Photomicrograph of a cryo-section of the dentate gyrus of $\mathbf{A}$ - Control rats, $\mathbf{B}$ - Diabetic group, C - Diabetic exercise group and $\mathbf{D}$ - Diabetic metformin-treated group showing positive immunoreactivity of neurons in the form of brown staining of cytoplasmic tau protein (interrupted arrows) (Immunohistochemical stain, Counterstained with $\mathrm{Hx}$., 200x)

\section{Immunohistochemistry for hippocampal tau protein}

The results of our work showed a significant increase in hippocampal tau-positive cells in diabetic (+215.5\%), exercise (+126.1\%), and metformin-treated $(+171.2 \%)$ groups compared to the control group. In comparison to the number of tau-positive cells in the diabetic group, the exercise group showed a significant fewer positively staining cells $(28.35 \%)$, while there was no significant reduction in metformin-treated rats. Interestingly enough, when we compared the metformin-treated group to the exercise group, we found a robust fewer hippocampal tau-positive cells in the brain of the latter group of rats $(-19.95 \%)$ (Table I and Figures 11 and 12).

\section{Discussion}

Type 2 DM is associated with dysregulation of the insulin signaling pathway, reduction of neuronal proliferation and synaptic plasticity, and downregulation of melatonin receptors in rat hippocampus. These insulin-induced molecular dysregulations result in learning and memory deficits, as well as general impairment of cognitive functions $[1,31]$. Our results, in line with work published by others, showed a significant impairment of cognitive functions in diabetic albino rats compared to the non-diabetic control group, as measured by lower latency in step-down avoidance test in the diabetic group. Noticeably, this latency was significantly higher in exercise and metformin-treated rats compared to the diabetic group. Exercise has been shown to improve motor and cognitive functions in rats by activating PI3-kinase/protein kinase B pathway [32, 33], which subsequently reduces blood glucose levels and induces hippocampal neuroblast cell proliferation [34].

These effects can be explained by the antioxidant effects of regular exercise, as well as the improved adaptive and cellular responses, together with the increased production of variable neurotrophic and antioxidant substances, most notably, the brain-derived neurotrophic factors, which lead to enhanced synaptogenesis, improved synaptic plasticity, and decreased neuronal apoptosis [35].

Chronic hyperglycemia is directly associated with neuronal apoptosis of the hippocampus, which can be reverted with metformin. Metformin leads to reduced expression of the pro-apoptotic protein Bax and increased expression of the antiapoptotic protein $\mathrm{Bcl} 2$ [36]. Metformin also in- 
creased neuronal growth factor, which is vital for the neuronal survival and differentiation of cells in the CNS [37].

The serum and brain glucose levels showed a significant increase in diabetic, exercised, and metformin-treated groups compared to the control group. Fasting insulin levels can strongly stimulate brain glucose metabolism by increasing cellular glucose uptake, enhancing glucose transporters 1,2 , and 4 to get attached to the plasma membrane [38, 39].

The exercised and metformin-treated groups showed a significant decrease in serum and brain glucose compared to the diabetic group. Exercise improves insulin resistance and modulates insulin signaling, leading to increased glucose uptake $[40,41]$. It also enhances the cellular processes involved in the skeletal muscle cellular turnover and proliferation, differentiation, motility, survival, and intracellular trafficking through the activation of various intracellular signaling mechanisms, including the AMPK and PI3 kinase/AKT pathways [42].

The results of recent research studies revealed that dietary modification, together with a regular exercise program, can improve certain aspects of pathological consequences associated with DM, including endothelial dysfunction, as well as insulin resistance, a finding supported with several recent aging-related studies. Physical activity can revert insulin resistance through activating IR and IRS proteins, together with the stimulation of insulin-independent signaling pathways [43], leading to the preservation of the $\beta$-cell mass and the prevention of islet cell exhaustion [44].

Regular physical exercise induced a significant increase in the pancreatic islet size and insulin secretion [45]. This effect is mediated through adenosine receptor stimulation in pancreatic islets $\beta$-cells [46]. Metformin increases $\beta$-cell sensitivity to glucose and protects $\beta$-cell mass [47]. It reduces insulin-mediated hepatic glucose production and increases peripheral glucose disposal [48]. It stimulates AMPK, which downregulates gluconeogenesis [49]. AMPK activators improve the glucose profile in type $2 \mathrm{DM}$ by suppressing hepatic glucose output $[49,50]$.

Diabetes mellitus is associated with decreased levels of serum insulin, increased lipolysis in adipose tissue, increased fatty acid content in the liver, and increased synthesis of endogen triglycerides [51]. The serum FFA in diabetic, exercised, and the metformin-treated groups showed a significantly higher level compared to the control group. The diabetic state inhibits the tissue lipase, which increases serum FFA, in turn increasing insulin resistance [52]. The serum FFA in exercised and the metformin-treated groups showed a significantly lower level in comparison to the diabetic group. The fatty acid oxidation is increased during low-intensity exercise and progressively decreases when the exercise intensity is further increased [53]. Moderate intensity exercise led to increased delivery of FFA to the exercising muscles and increased FFA oxidation [54]. Regular physical exercise increased the breakdown of intramuscular triglycerides, delivery of fatty acids to exercising muscles, movement of fatty acids across the muscle membrane, and movement of fatty acids across the mitochondrial membrane [55]. Metformin decreased the levels of TGs, cholesterol, LDL-cholesterol, and FFA [56], through AMPK-mediated inhibition of adipocytes hormone-sensitive lipase [57].

The serum cholesterol showed a significant higher levels in diabetic, exercised, and metformin-treated groups in comparison to the control group. The inhibited activity of lipoprotein lipase caused by insulin resistance elevates levels of total cholesterol in diabetic rats [40]. Controlling blood glucose improves the total cholesterol rise in diabetic patients [58]. In our study, there was a significant lower levels of serum cholesterol in exercised and the metformin-treated groups compared to the diabetic group. Regular exercise had a significant reducing effect on total cholesterol in rats with T2D through activation of the AMPK and PI3K downstream pathway [41].

The diabetic and exercised groups also showed a significant higher levels of the serum TGs compared to the control group. However, serum TGs showed a considerable lower levels in exercised and metformin-treated groups compared to the diabetic group. Exercise decreases plasma and liver TGs by improving the activity of antioxidant enzymes and reduces obesity-induced oxidative stress [59]. Moderate intensity exercise led to TGs breakdown and increased FFA oxidation [55]. Through activation of the AMPK pathway, metformin overcomes the inhibitory effect of diacylglycerol exerted on AMPK, which leads to glucose disposal and serum lipids reduction in turn [60].

The serum LDL showed a significant lower levels in exercised and metformin-treated groups compared to the diabetic group. This can be attributed to the increased activity of lipoprotein phospholipase A2 [61]. Proprotein convertase subtilisin/Kexin 9 (PCSK9) decreases liver absorption and oxidation of LDL. Exercise is associated with reduced levels of PCSK9 and its gene expression [62]. Metformin therapy decreases insulin resistance in skeletal muscles, possibly by inhibiting miR21, which acts as a post-translational regulator. MiR21 was recently linked to insulin resistance in skeletal muscles and adipocytes [63].

The serum HDL showed a significant higher levels in exercised and metformin-treated groups compared to the diabetic group. This finding could be explained by the increased expression 
of ATP-binding cassette transporter A-1 that has a strong effect on increasing plasma HDL [64] and by increasing insulin sensitivity by metformin [65].

It is well accepted that memory is intimately associated with the plasticity of neuronal synapses in the hippocampus [66]. In our study, the granular cells of the dentate gyrus region were significantly fewer in diabetic, exercised, and metformin-treated groups compared to the control group. However, the numbers of the dark cells, at risk of developing cell death [67] (pyknosis), and degenerated cells were significantly greater in diabetic, exercised, and metformin-treated groups compared to the control group.

The diabetic animals' hippocampal environment favors apoptosis [68]. Activation of caspases represents an irreversible point in the cell death process. Caspase regulation occurs by extrinsic or intrinsic signaling pathways [69]. There is evidence demonstrating that the experimental diabetes model had hippocampal apoptosis resulting from caspase-dependent mechanisms [70, 71]. Anarkooli et al. found increased caspases-3 activity in the hippocampus of STZ-induced diabetic rats after eight weeks [72]. The increase in the number of degenerated cells is explained by hyperglycemic-stimulated free radical production via glucose oxidation, nonenzymatic proteins glycation, and glycated proteins' oxidative degradation [73]. A weak body defense system becomes unable to counteract the enhanced reactive oxygen species (ROS) generation, and an imbalance between ROS and their protection occurs, which damages the cellular organelles and enzymes, and increases lipid peroxidation with insulin resistance development [74, 75].

The hippocampal $A \beta-42$ and $A \beta-42$ immunohistochemically stained positive cells showed a significant greater number in diabetic, exercised, and metformin-treated groups compared to the control group. However, there was a significant fewer cells in exercised and metformin-treated groups compared to the diabetic group. The diabetic groups' considerable greater number of cells could be attributed to the translational upregulation of the $\beta$-secretase enzyme and its substrate, amyloid precursor protein [76]. The increased level of plasma lipids is associated with insulin resistance [77]. Exercise decreases $\beta$-secretase one protein content and activity with an accompanying decline in AMPK phosphorylation as well as Akt and MAPK phosphorylation, leading to inhibition of the $D M$-induced $A \beta$ accumulation and memory deficit [78]. Exercise can increase lipoprotein receptor-related protein-1 levels in the hippocampus of $A D$ transgenic mice and reduce the levels of soluble $A \beta$ protein [79]. Metformin-induced AMPK activation may inhibit the downstream mTOR signaling, thus promoting autophagy and lysosomal degra- dation of $A \beta$ [80]. Metformin also enhances AMPK expression through increased transcript levels of both Bcl-2 and CREP protein [81]. Metformin, by AMPK activation, provides phosphorylation of the PGC1 $\alpha$ protein, which can control anti-apoptotic genes that are inhibited by $A \beta-42$ [82].

The hippocampal tau-positive cells showed a significant greater numbers in diabetic, exercised, and metformin-treated groups compared to the control group. Diabetes increased tau phosphorylation due to insulin resistance through IRS-1, extracellular signal-related kinase (ERK)/MAPK, and PI3 kinase/Akt pathways [83]. Cerebral insulin resistance leads to over-activation of the important tau phosphorylation-regulator glycogen synthase kinase-3 $\beta$, which was normalized by the administration of intranasal insulin normalized cerebral glycogen synthase kinase 3 (GSK-3) levels and reduced cerebrospinal fluid (CSF) tau levels [84].

The results also showed that there was a significant fewer number of tau-positive cells in the exercised group compared to both the diabetic and metformin-treated groups. Exercise suppresses hyperphosphorylation of tau in the hippocampus by decreasing GSK-3 $\beta$ activity through PI3 kinase/ Akt pathway activation [1]. It also increases Wnt3 expression and suppresses GSK-3 $\beta$ expression by activating the Wnt signaling pathway, which causes inhibition on GSK-3 $\beta$ expression [51].

In conclusion, treadmill exercise training and metformin, besides their metabolic effects, caused regression of biomarkers of Alzheimer's disease, protecting the hippocampus functions against DM-induced memory deterioration. This effect was achieved mostly through upregulating the insulin signaling pathways in the brain. Further investigations are required to emphasize such effects and to find out new possible mechanisms.

\section{Conflict of interest}

The authors declare no conflict of interest.

\section{References}

1. Kim DY, Jung SY, Kim TW, Lee KS, Kim K. Treadmill exercise decreases incidence of Alzheimer's disease by suppressing glycogen synthase kinase- $3 \beta$ expression in streptozotocin-induced diabetic rats. J Exerc Rehabil 2015; 11: 87-94.

2. Kayar $\mathrm{Y}$, Agin $\mathrm{M}$. The relationship between demographic and anthropometric characteristics and diabetic complications and number of hospitalizations in hospitalized diabetic patients. Arch Med Sci Civil Dis 2019; 4: e7-15.

3. Sebastião I, Candeias E, Santos MS, de Oliveira CR, Moreira PI, Duarte Al. Insulin as a bridge between type 2 diabetes and Alzheimer disease - how anti-diabetics could be a solution for dementia. Front Endocrinol 2014; 5: 110.

4. Chang W, Huang D, Lo YM, et al. Protective effect of caffeic acid against Alzheimer's disease pathogenesis 
via modulating cerebral insulin signaling, $\beta$-amyloid accumulation, and synaptic plasticity in hyperinsulinemic rats. J Agric Food Chem 2019; 67: 7684-93.

5. Nakabeppu Y. Origins of brain insulin and its function. In: Diabetes Mellitus (pp. 1-11). Springer, Singapore 2019.

6. Konishi M, Sakaguchi M, Lockhart SM, et al. Endothelial insulin receptors differentially control insulin signaling kinetics in peripheral tissues and brain of mice. Proc Natl Acad Sci 2017; 114: E8478-E87.

7. Reddy PH, Tonk S, Kumar S, et al. A critical evaluation of neuroprotective and neurodegenerative MicroRNAs in Alzheimer's disease. Biochem Biophys Res Commun 2017; 483: 1156-65

8. Stoeckel LE, Arvanitakis Z, Gandy S, et al. Complex mechanisms linking neurocognitive dysfunction to insulin resistance and other metabolic dysfunction. F1000Res 2016; 5: 353

9. Kulas JA, Franklin WF, Smith NA, et al. Ablation of amyloid precursor protein increases insulin-degrading enzyme levels and activity in brain and peripheral tissues. Am J Physiol Endocrinol Metab 2019; 316: E106-E20.

10. Karstoft K, Pedersen BK. Exercise and type 2 diabetes: focus on metabolism and inflammation. Immunol Cell Biol 2016; 94: 146-50.

11. Barnes JN. Exercise, cognitive function, and aging. Adv Physiol Educ 2015; 39: 55-62.

12. Inzucchi SE, Bergenstal RM, Buse JB, Diamant M, Ferrannini $E$, Nauck $M$. Management of hyperglycemia in type 2 diabetes: a patient-centered approach: position statement of the American Diabetes Association (ADA) and the European Association for the Study of Diabetes (EASD). Diabetes Care 2012; 35: 1364-79.

13. Shek A, Alieva R, Kurbanov R, Hoshimov S, Nizamov U, Ziyaeva A. Can metformin stabilize PCSK9 level in stable coronary artery disease patients treated with statins? Arch Med Sci Atheroscler Dis 2019; 4: 144-50.

14. Koenig AM, Mechanic-Hamilton D, Xie SX, et al. Effects of the insulin sensitizer metformin in Alzheimer's disease: Pilot data from a randomized placebo-controlled crossover study. Alzheimer Dis Assoc Disord 2017; 31 107-13.

15. Rena G, Hardie DG, Pearson ER. The mechanisms of action of metformin. Diabetologia 2017; 60: 1577-85.

16. Kumar P, Baquer N. Alterations of metabolic parameters and antioxidant enzymes in diabetic aging female rat brain: Neuroprotective role of metformin. J Neurol Sci 2017; 381: 573

17. Reed MJ, Meszaros K, Entes LJ, et al. A new rat model of type 2 diabetes: the fat-fed, streptozotocin-treated rat. Metabolism 2000; 49: 1390-4.

18. Reagan-Shaw S, Nihal M, Ahmad N. Dose translation from animal to human studies revisited. FASEB J 2008; 22: 659-61.

19. Kim DY, Jung SY, Kim K, Kim CJ. Treadmill exercise ameliorates Alzheimer disease-associated memory loss through the Wnt signaling pathway in the streptozotocin-induced diabetic rats. J Exerc Rehabil 2016; 12: 276-83.

20. Henry RJ. Clinical Chemistry, Principles and Technics. Harper and Row Publishers, New York 1964.

21. Sfa C. 96-well serum/plasma fatty acid kit non-esterified fatty acids detection 1,000 point kit. ZenBio 2010; 692: 1-6.

22. Young DS. Effects of diseases on clinical lab tests. $4^{\text {th }}$ ed. AACC 2010
23. Fossati P, Prencipe L. Serum triglycerides determined colorimetrically with an enzyme that produces hydrogen peroxide. Clin Chem 1982; 28: 2077-80.

24. Fray AE, Forsyth RJ, Boutelle MG, Fillenz M. The mechanisms controlling physiologically stimulated changes in rat brain glucose and lactate: a microdialysis study. J Physiol 1996; 496: 49-57.

25. Best JD, Jay MT, Otu F, et al. Quantitative measurement of changes in amyloid- $\beta$ (40) in the rat brain and cerebrospinal fluid following treatment with the $\gamma$-secretase inhibitor LY-411575 [N2-[(2S)-2-(3,5-difluorophenyl)2-hydroxyethanoyl]-N1-[(7S)-5-methyl-6-oxo-6,7-dihydro-5H-dibenzo[b,d]azepin-7-yl]-L-alaninamide]. J Pharmacol Exp Ther 2005; 313: 902-8.

26. Li J, Qi Y, Liu H, et al. Acute high-altitude hypoxic brain injury: Identification of ten differential proteins. Neural Regen Res 2013; 8: 2932-2941.

27. Salkovic-Petrisic M, Osmanovic-Barilar J, Brückner MK, Hoyer S, Arendt T, Riederer P. Cerebral amyloid angiopathy in streptozotocin rat model of sporadic Alzheimer's disease: a long-term follow up study. J Neural Trans 2011; 118: 765-72.

28. Jung SY, Kim DY, Yune TY, Shin DH, Baek SB, Kim CJ. Treadmill exercise reduces spinal cord injuryinduced apoptosis by activating the PI3K/Akt pathway in rats. Exp Ther Med 2014; 7: 587-93.

29. Sung YH, Shin MS, Cho S, et al. Depression-like state in maternal rats induced by repeated separation of pups is accompanied by a decrease of cell proliferation and an increase of apoptosis in the hippocampus. Neurosci Lett 2010; 470: 86-90.

30. Chan YH. Biostatistics 102: quantitative data - parametric \& non-parametric tests. Blood Press 2003; 140: 79.

31. Wongchitrat P, Lansubsakul N, Kamsrijai U, Sae-Ung K, Mukda S, Govitrapong P. Melatonin attenuates the high-fat diet and streptozotocin-induced reduction in rat hippocampal neurogenesis. Neurochem Int 2016; 100: 97-109.

32. Medhat E, Rashed L, Abdelgwad M, Aboulhoda BE, Khalifa MM, El-Din SS. Exercise enhances the effectiveness of vitamin D therapy in rats with Alzheimer's disease: emphasis on oxidative stress and inflammation. Metab Brain Dis 2020; 35: 111-20.

33. Jung SY, Kim DY. Treadmill exercise improves motor and memory functions in cerebral palsy rats through activation of PI3K-Akt pathway. J Exerc Rehabil 2017; 13: 136-142.

34. Yi SS. Effects of exercise on brain functions in diabetic animal models. World J Diabetes 2015; 6: 583-97.

35. Paillard T. Preventive effects of regular physical exercise against cognitive decline and the risk of dementia with age advancement. Sports Med Open 2015; 1: 20.

36. Chen B, Teng Y, Zhang X, Lv X, Yin Y. Metformin alleviated $A \beta$-induced apoptosis via the suppression of JNK MAPK signaling pathway in cultured hippocampal neurons. Biomed Res Int 2016; 2016: 1421430.

37. Oliveira WH, Nunes AK, França MER, et al. Effects of metformin on inflammation and short-term memory in streptozotocin-induced diabetic mice. Brain Res 2016; 1644: $149-60$

38. Grillo CA, Woodruff J, Macht VA, Reagan LP. Insulin resistance and hippocampal dysfunction: Disentangling peripheral and brain causes from consequences. Exp Neurol 2019; 318: 71-7.

39. Olver TD, Laughlin MH, Padilla J. Exercise and vascular insulin sensitivity in the skeletal muscle and brain. Exerc Sport Sci Rev 2019; 47: 66-74. 
40. Liu Y, Liu C, Lu ML, et al. Vibration exercise decreases insulin resistance and modulates the insulin signaling pathway in a type 2 diabetic rat model. Int I Clin Exp Med 2015; 8: 13136-44.

41. Andrade EF, Lima ARV, Nunes IE, et al. Exercise and beta-glucan consumption (Saccharomyces cerevisiae) improve the metabolic profile and reduce the atherogenic index in type 2 diabetic rats (HFD/STZ). Nutrients 2016; 8: 792.

42. Wang $\mathrm{Q}, \mathrm{Hu}$ J, Liu $\mathrm{Y}$, et al. Aerobic exercise improves synaptic-related proteins of diabetic rats by inhibiting FOXO1/NF-KB/NLRP3 inflammatory signaling pathway and ameliorating PI3K/Akt insulin signaling pathway. J Mol Neurosci 2019; 69: 28-38.

43. Tan J, Guo L. Swimming intervention alleviates insulin resistance and chronic inflammation in metabolic syndrome. Exp Ther Med 2019; 17: 57-62.

44. Teixeira-Lemos E, Nunes S, Teixeira F, Reis F. Regular physical exercise training assists in preventing type 2 diabetes development: focus on its antioxidant and anti-inflammatory properties. Cardiovasc Diabetol 2011; 10: 12.

45. Ding C, Chooi YC, Chan Z, et al. Dose-dependent effects of exercise and diet on insulin sensitivity and secretion. Med Sci Sports Exerc 2019; 51: 2109-16.

46. Otero-Losada M, Gonzalez J, Müller A, et al. Exercise ameliorates endocrine pancreas damage induced by chronic cola drinking in rats. PLoS One 2016; 11: 0155630.

47. Wyett G, Gibert Y, Ellis M, Castillo HA, Kaslin J, Aston-Mourney K. Metformin, beta-cell development, and novel processes following beta-cell ablation in zebrafish. Endocrine 2018; 59: 419-25.

48. Tomkin GH, Owens D. Diabetes and dyslipidemia: characterizing lipoprotein metabolism. Diabetes Metab Syndr Obes 2017; 10: 333-43.

49. Rutter GA, Pullen TJ, Hodson DJ, Martinez-Sanchez A. Pancreatic $\beta$-cell identity, glucose sensing and the control of insulin secretion. Biochem J 2015; 466: 203-218.

50. Edmunds LR, Huckestein BR, Kahn M, et al. Hepatic insulin sensitivity is improved in high-fat diet-fed Park2 knockout mice in association with increased hepatic AMPK activation and reduced steatosis. Physiol Rep 2019; 7: e14281.

51. Mohammadimanesh A, Vahidiniya AA, Doaei S, et al. The effect of different types of honey on the lipid profile of streptozotocin-induced diabetic rats. Arch Med Sci Atheroscler Dis 2019; 28: e113-8.

52. Barchuk M, Schreier L, López G, et al. Glycosylphosphatidylinositol-anchored high density lipoprotein-binding protein 1 and angiopoietin-like protein 4 are associated with the increase of lipoprotein lipase activity in epicardial adipose tissue from diabetic patients. Atherosclerosis 2019; 288: 51-9.

53. Spriet LL. New insights into the interaction of carbohydrate and fat metabolism during exercise. Sports Med 2014; 44: 87-96.

54. Kim JH, Park Y. Combined effects of phytochemicals and exercise on fatty acid oxidation. J Exerc Nutrition Biochem 2016; 20: 20-6.

55. Iso T, Sunaga $H$, Matsui $H$, et al. Serum levels of fatty acid binding protein 4 and fat metabolic markers in relation to catecholamines following exercise. Clin Bioch 2017; 50: 896-902.

56. Khunti K, Ceriello A, Cos X, De Block C. Achievement of guideline targets for blood pressure, lipid, and glycaemic control in type 2 diabetes: a meta-analysis. Diabetes Res Clin Pract 2018; 137: 137-148.
57. Zhao W, Li A, Feng X, et al. Metformin and resveratrol ameliorate muscle insulin resistance through preventing lipolysis and inflammation in hypoxic adipose tissue. Cell Signal 2016; 28: 1401-11.

58. Tsuzuki T, Shinozaki S, Nakamoto H, et al. Voluntary exercise can ameliorate insulin resistance by reducing iNOS-mediated S-nitrosylation of Akt in the liver in obese rats. PLoS One 2015; 10: 0132029.

59. Baur JA, Birnbaum MJ. Control of gluconeogenesis by metformin: does redox trump energy charge? Cell Metab 2014; 20: 197-9.

60. Cai R, Huang R, Han J, et al. Lipoprotein-associated phospholipase $A 2$ is associated with risk of mild cognitive impairment in Chinese patients with type 2 diabetes. Sci Rep 2017; 7: 1-9.

61. Wang Y, Xu D. Effects of aerobic exercise on lipids and lipoproteins. Lipids Health Dis 2017; 16: 132.

62. Wang J, Gao Y, Duan L, et al. Metformin ameliorates skeletal muscle insulin resistance by inhibiting miR-21 expression in a high-fat dietary rat model. Oncotarget 2017; 8: 98029.

63. Tofighi A, Rahmani F, Qarakhanlou BJ, Babaei S. The effect of regular aerobic exercise on reverse cholesterol transport A1 and apo lipoprotein al gene expression in inactive women. Iran Red Crescent Med J 2015; 17: 326321.

64. Zhang S, Xu H, Yu X, Wu YI, Sui D. Metformin ameliorates diabetic nephropathy in a rat model of low-dose streptozotocin-induced diabetes. Exp Ther Med 2017; 14: 383-90.

65. Kamenova P. Therapeutic potential of metformin in normal glucose tolerant persons with metabolic syndrome. Biotechnol Biotechnologic Equip 2020; 34: 30-7.

66. Yang L, Wu, Wang B, Bu X, Zhu J, Tang J. The effects of hyperbilirubinaemia on synaptic plasticity in the dentate gyrus region of the rat hippocampus in vivo. Arch Med Sci 2019; 16: 200-4.

67. Sadeghi A, Hami J, Razavi S, Esfandiary E, Hejazi Z. The effect of diabetes mellitus on apoptosis in hippocampus: cellular and molecular aspects. Int J Prev Med 2016; 7: 57

68. Kahya MC, Nazıroğlu M, Övey is. Modulation of diabetes-induced oxidative stress, apoptosis, and Ca 2+ entry through TRPM 2 and TRPV 1 channels in dorsal root ganglion and hippocampus of diabetic rats by melatonin and selenium. Mol Neurobiol 2017; 54: 2345-60.

69. Fritsch M, Günther SD, Schwarzer R, et al. Caspase-8 is the molecular switch for apoptosis, necroptosis and pyroptosis. Nature 2019; 575: 683-7.

70. Yan W, Pang M, Yu Y, et al. The neuroprotection of liraglutide on diabetic cognitive deficits is associated with improved hippocampal synapses and inhibited neuronal apoptosis. Life Sci 2019; 231: 116566.

71. Yonguc GN, Dodurga Y, Adiguzel E, et al. Grape seed extract has superior beneficial effects than vitamin $\mathrm{E}$ on oxidative stress and apoptosis in the hippocampus of streptozotocin induced diabetic rats. Gene 2015; 555: 119-26.

72. Jafari Anarkooli I, Sankian M, Ahmadpour S, Varasteh $\mathrm{AR}$, Haghir $\mathrm{H}$. Evaluation of $\mathrm{BCl}-2$ family gene expression and Caspase- 3 activity in hippocampus STZ-induced diabetic rats. Exp Diabetes Res 2008; 2008: 638467.

73. Karunakaran U, Park KG. A systematic review of oxidative stress and safety of antioxidants in diabetes: focus on islets and their defense. Diabetes Metab J 2013; 37: 106-12.

74. Oyenihi AB, Ayeleso AO, Mukwevho E, Masola B. Antioxidant strategies in the management of diabetic neuropathy. Biomed Res Int 2015; 2015: 515042. 
75. Devi L, Alldred MJ, Ginsberg SD, Ohno M. Mechanisms underlying insulin deficiency-induced acceleration of $\beta$-amyloidosis in a mouse model of Alzheimer's disease. PLoS One 2012; 7 : e32792.

76. Busquets $\mathrm{O}$, Ettcheto $\mathrm{M}$, Pallàs $\mathrm{M}$, et al. Long-term exposition to a high fat diet favors the appearance of $\beta$-amyloid depositions in the brain of $\mathrm{C} 57 \mathrm{BL} / 6 \mathrm{~J}$ mice. A potential model of sporadic Alzheimer's disease. Mech Ageing Dev 2017; 162: 38-45.

77. MacPherson RE, Baumeister P, Peppler WT, Wright DC, Little JP. Reduced cortical BACE1 content with one bout of exercise is accompanied by declines in AMPK, Akt, and MAPK signaling in obese, glucose-intolerant mice. J Appl Physiol (1985) 2015; 119: 1097-104.

78. Lin TW, Shih YH, Chen SJ, et al. Running exercise delays neurodegeneration in amygdala and hippocampus of Alzheimer's disease (APP/PS1) transgenic mice. Neurobiol Learn Mem 2015; 118: 189-97.

79. Zeng B, Zhao G, Liu HL. The differential effect of treadmill exercise intensity on hippocampal soluble $\alpha \beta$ and lipid metabolism in APP/PS1 mice. Neuroscience 2020; 430: 73-81.

80. Chiang MC, Cheng YC, Chen SJ, Yen CH, Huang RN. Metformin activation of AMPK-dependent pathways is neuroprotective in human neural stem cells against Amyloid-beta-induced mitochondrial dysfunction. Exp Cell Res 2016; 347: 322-31.

81. Markowicz-Piasecka M, Sikora J, Mateusiak Ł, Mikiciuk Olasik E, Huttunen KM. New prodrugs of metformin do not influence the overall haemostasis potential and integrity of the erythrocyte membrane. Eur J Pharm 2017; 811: 208-21.

82. Moran C, Beare R, Phan TG, Bruce DG, Callisaya ML, Srikanth V. Type 2 diabetes mellitus and biomarkers of neurodegeneration. Neurology 2015; 85: 1123-30.

83. Zhang Y, Huang NQ, Yan F, et al. Diabetes mellitus and Alzheimer's disease: GSK-3 $\beta$ as a potential link. Behav Brain Res 2018; 339: 57-65.

84. Yang Y, Ma D, Wang Y, et al. Intranasal insulin ameliorates tau hyperphosphorylation in a rat model of type 2 diabetes. J Alzheimers Dis 2013; 33: 329-38. 